I. The Origin of Japanese Way of Thinking

1. Natural Climate

It is said that Japanese attitude towards nature is particularly to cope with it naturally in accordance with the rules of nature. Such attitude which is related to the beauty of Japanese climate with four seasons makes Japanese people friendly to nature but not opponent to it. And such wisdom of Japanese primitive disposition has regulated as one side of Japanese disposition.

For example, Japanese people regarded their own death the same as that of nature, or they fitted themselves to the nature's cycle and accepted all conditions of living circumstances to meet with the nature. This shows their strong inclinations to the affirmation of the reality. Besides, they regarded this phenomenal world as an absolute existence, or they acknowledged the endless continuration between the death and the revival, and as its medium, they made much of solemn ceremonies. This also shows the same way of thinking. Here, we can find the theory of Japanese primitive disposition.

Since geographically Japan is situated outside of interchanges among foreign countries naturally there exists only one border, one race, one language and one culture. So, from the beginning Japan has kept the conditions of the ascent of national conscience and unity. But Japan was rather weak in the national conscience, notwithstanding the unified nation, comparing with other foreign countries where people had to make effort to keep firm national consciences.

2. Cultural Climate

(1) human relationship

Japanese climate has been governed by severe monsoons, so they 
are obliged to cope with the violence of the nature by people's unity and cooperation. And the inclination of making friendly human relations originated from this working together in agriculture. So on the contrary obstructing this cooperative cultivation was regarded as a crime. As a matter of fact such an inclination of making much of humanity came from this peculiar climate in Japan.

From this relationship between nature and people, the theory of special human relationship came into exsistance and their way of thinking that the phenomenon means essence was produced. Also from here it can be said that in the Japanese society giri or an obligation means a principle and ninjo or a sympathy is their real feeling. It shows that giri exists as the phenomenal relationship among persons. Therefore, in this relationșhip the mutual subjective vay of taking part was especially made much and they acted according to tre mutual understanding and reliance of the mutual subject. Such zction was not always logical or positive but irrational, and was art to ke intuitive and emotional.

Because of such way of thinking moral 'good and evil' had the tendency of being caught in relation with other people or moral relation with the whole but not in relation with interests or fortune anj misfortune. To sacrify themselves for their iamily, their iora cr their government was counted as the supreme virtue, wrich also came from that inclination.

Though the Japanese society has only vertical humin relations, the reason why it is working even now is because it is line and we can find Japanese peculiarity in the fact that success in life beyond social status or class is greatly possible in this world lined and arranged to some degree. Therefore, the change of the Japanese so- 
cial organization could be done slowly just like payment by install mencs.

Anyhow Japanese human relationship has an unique strength not only personally but also socially in this lined vertical relations and has one logic in its front and back sides. In this dual relationship there could be the appearance of the opportunity of Japanese disposition. This is also matched to the Japanese posture facing inside or ushiromuki and turning their back upon the enemy, which can be aiscussed later in this paper.

(2) characteristics of the Japanese language.

In Japanese sentences omissions of subjects are often seen. By doing this the meanings and contents of the sentences become indistinct and also this could cause misunderstandings. The reason why Jacanese can understand each other even without subjects is because -he zelationship between oneself and others is fused and an intuitive urderstanding exists preceding their language. Besides Japanese anguage has no relative pronouns nor infinitives, which restricts the logical development of thinking. So comparing with other foreign languages Japanese language does not fit for scientific expressions in many cases.

Adding to it, European and American languages state yes or no to the objective Eacts, but in Japanese yes or no expresses intention and feeling to the opposite persons; it is not the answer to a fact but the feeling toward a person. In this way Japanese people make ruch of the relationship between people rather than objective facts, and they don't watch Eacts objectively by detaching the relations with the zeople concerned. This attitude is also the characteristics of the language. Such an attitude means an obstacle for logical and 
scientific thinking. On the other hand it is quite convenient for expressing individuality emotionally and intuitively. In the expressive styles such as poems and songs where much implications are included between lines, illogical factors and emotional feelings are emphasized. In no play or a Japanese classical drama or sumie or a Japanese classical brush painting expressions behind the words have more active meanings than the words themselves.

The control of these unconscious promises or rules which people should keep is quite strong in the Japanese society. This might show the Japanese language is not autonomous enough as a language system, which affects Japanese people's way of thinking.

\section{Japanese Way of Thinking and Sports}

The peculiarity of Japanese disposition can be seen with the above-mentioned characteristics synthetically. The same phenomena appear concerning attitude towards sport by Japanese people. Here I would like to pick up some of the typical ways of thinking in Japan.

1. the way of thinking omote or front and ura or back and sports It is said that the consciousness of front and back namely tatemae or a principle and honne or a real feeling exists in Japan. Here the front culture means a public and systematic culture and the back culture means a private and non-systematic culture.

In the Japanese culture the front one is considered uso or a lie and the back one is called honmono or real thing. In the tea ceremony or the flower arrangement ura-senke or the back school is much more popular than omote-senke or the front school. Even having our parties or gatherings, we also could know each other's real feel- 
ings better in the second spree. In Japan even if we get to have some frustrations in the public places we could dissolve them in the back society. Even in the back society there is an order in its own and the contact with the front world is said to be kept closely all the time.

From such a way of thinking Japanese sports clubs might be called a back culture group. If you are a member of a university sport club, your senior will give you advice as much as possible when you are in trouble and he might even find you a job.

2. the culture of hist or shame and sport

Toshinobu Yasunaga says : the depth of Japaliese nature, tryi..: hard to fuse with the outer world, produced these common expressions; "Select a big tree for your shelter" or "Yield to the powerful." And at the same time the culture of shame is the origin of the nature of the nature of the quick response adaptability and hospitality which are extraordinarily strong among Japanese people.

This culture of shame is also said to be from the fact that Japan is the country of many gods. So Japanese moral sense is not to act according to the conscience of the God but to avoid a shame in front of others. This Japanese nature of being anxious about his reputation is broadly spread as a Japanese basic feeling. This also explains the phenomenon that after graduating from school Japanese women become indifferent to sports or are anxious about their bad reputations by participating in sports.

3. the attitude of ushiromuki or showing his back and sports Yuji Aida says: Japanese defense posture is just showing his 
back to the enemy and facing inside dropping his head down. As a Japanese husband is called "the lord of back," a protector is especially a person who protects some one with his back and the Japanese idea that an attack is done from the back is very strong. Japanese folk danaing is performed facing everyone into the same direction. This seems to me to have some relations to Japanese introversion.

4. the hasty temper (short term taget) and sports

When a Japanese finds some concrete targets in front of him, he tries to achieve it as hard as possible. But on the other hand he is so quick-tempered that he can not reflect it on his own life according to objective facts. Because of this way of thinking, I beleive that Japanese accepted foreign thoughts and cultures without any criticism from the ancient times. Also in sports there is an inclination to pursue imported sports in various fields. This is also from this Japanese way of thinking.

\section{5. the theory of 'become' and sports}

The theory of becoming in the old days continues to exist in ceremonies which fuse the relation between nature and people in the community. But when these ceremonies collapsed in the modern times this theory of becoming was buried, and in place of this the theory of nariyukimakase of leaving it to take its own course or nashikuzushi or amortize gained power. Here I would like to find a chance to create Japanese national sports in reproducing this Japanese theory of becoming against Eurcpean theory of producing. 
6. sabi, elegant simplicity, and wabi or quiet taste and sports As I mentioned before, Japanese didn't like complex symbols from the older days, but they like simple and artless symbols. So the shrines were made of simple plain wood and in the rooms of the tea ceremony we can feel simplicity more than anything else. But as seen in Zen Buddhism or at vacant space of oriental architectures and drawings Japanese tried to find some important significance in this simplicity where endless complexity exists. It is well-known that such zen Buddhism gave influence on bushido or a Japanese chivalry. It might be because samurais were attracted by the plain and simple lives of zen priests.

In "the construct of Iki" by Shuzo kuki, Japanese mentality concerning human relations is taken as $\underline{i k i}$ or being smart. And he classified iki into three groups; (I) a scandalous condition(selfpossible relation to the opposite sex), (2) being obstinate(selfmaterial value) and (3) abandonment(self-destiny, mutability.) And he indicates that samurais were quite satisfied with the simple life which was not restricted from the material values, calling it inase or $\underline{\text { isami }}$ or being smart and courageous. Namely since the principles of Zen Buddhism are simple and artless, samurais threw themselves into the mental training of Zen Buddhism.

Such charactaristics is still alive even now in the concept of the michi or moral principles of budo or a military art such as archery, fencing, judo and so on. It can also be seen easily in jutsu or a technique such as iai or karate.

7. mushin or innocence and sports Having one's mind come to nothing is just like clarifying the 
surface of the water. By doing this we can easily reflect minds of others on the surface, which is called meikyoshisui or the clear mirror like a surface of the stagnant water in Chinese. Tateo Doi grasps this as amae or being spoiled. Amae neans to presume upon another's love and its foundamental attitude of the spirit is passive and our mind is completely occupied by the opposote person." Such a state can be seen in various field of sports. Especially the above-mentioned budo might be a very good example of this phenomenon.

8. making absolute and sports

Making absolute can be also expressed as making non-relative. The reason why Japanese dislike making relative is because they dislike looking themselves objectively. This Japanese dislikeness seems to have arisen from the introversion or the emotionai inclination which is mentioned before, and it is airectly connected to the nationalism or the worship of the emperor.

And this is also related to the fact that Japanese are factional extremely introversive and make much of moral sides. This means making the peculiar moral associations absolute but this inclination is apt to disregard genral standards and Iaws. Here are some good examples; sportsmen show their tears when they win but they also do that when they are defeated. Japanese people go to the stadium to cheer their own school teams or favorite teams especially in case of national tournaments, but the ground and stadium after they left are covered with litters.

9. nagara and awase, being dual and sports 
Japanese people accepted foreign cultures sensitively, but just did that regarding foreign cultures as constituents of Japanese culture. Because of this, Japanese have its characteristics of being dual. Yuji Aida says this Japanese way of accepting other cultures is just like reducing somethings from the white paper, or not receiving all of the opposite person's experiences but thinking them by himself after accepting them. Certainly as the Japanese practical method they united complexed and contradictive contents of foreign cultures and making good use of each peculiarity, but on the other hand they were apt to yield to opportunism or eclecticism.

But Japanese are active. They simplified those peculiarities and did the device of making food use of them in their lives. the way of thirking of nagara or awase is the wisdom established there. People say Europe has the culture of separation and that Jaban ho= the culture of combination. Indeed, this shows the difference between the two very well.

Awaseru or to combine means to fit himself to the opposite, so this idea is connected with omoiyari or sympathy and sasshi or understanding without being told about the opposite person.

In the future classification and specialization will be pushed forward more and more. I an sure that someday their way of thinking which has the flexibility of nagara and awase would be greatly effective. Of course awase can give an unique room to the Iife of the earnest and bisy Japanese. The Japanese way of living with work and play at the same time and offical and private at the same time such as business and golf originated from this nagara and awase. 


\section{BIBLIOGRAPHY}

1. Gen Nakamura: The Way of Thinking by Oriental People, Vol.III Shunjusha, 1969

2. Hisanobu Yasunaga: The Source of National Mentality, "Bungaku" Janary, 1965

3. Yuji Aida" The Strukture of Consciousness of Japanese People Sociology, Yuhikaku, "Legal Sociology, No.ll"

4. Takao Sofue: The Japanese People, Shibun-do, 1971

6. Takenobu Kawashima" The Modern Society and the Laws, Iwanamishoten, 1972

7. Isaiah Ben Dasan" The Japanese and the Jews, Yamamoto-shoten 1967

8. Shuzo Kuki" The Construct of "Iki"(being smart), Iwanami-shoten, 1967

9. Takeo Doi: The Construct of "Amae" (being spoiled), Kobun-do, 1972

10. Takashi Kamei" Linguistic Considerations of the Emperor System of Japan, "Chuokoron", August, 1974

11. N.S.Timasheff, translated by Kawashima, Hayakawa and Ishimura: The Legal Sociology, Todai Shuppankai, 1962

12. James W. Keating: Sportmanship as a Moral Category, Ethics IXXV, pp. 25-35, 1964 